Supplement of

\title{
Dependence between the photochemical age of light aromatic hydrocarbons and the carbon isotope ratios of atmospheric nitrophenols
}

Marina Saccon et al.

Correspondence to: Marina Saccon (msaccon86@gmail.com)

The copyright of individual parts of the supplement might differ from the CC BY 4.0 License. 


\section{Part 1. Comparison of condensed phase reactions of phenols with gas phase loss by reaction with OH-radicals}

To our knowledge there are no studies of the chemical removal rate for nitrophenols in PM. Yu et

al. (2016) present information on reactions of reactive phenols in aqueous solutions under conditions somewhat similar to atmospheric conditions in fog or cloud water. In this publication the loss rate of phenol $\left(\mathrm{C}_{6} \mathrm{H}_{5} \mathrm{OH}\right)$ due to reaction with $\mathrm{OH}$ in the aqueous phase under simulated sunlight conditions is $0.05 \mathrm{~h}^{-1}$. The authors estimate that in their study the oxidant concentration in the aqueous phase is a factor of seven times of higher than for fog water at midday in winter at Davis (CA). The resulting loss rate in the condensed phase at midday in winter at Davis would thus be approximately $7 \times 10^{-3} \mathrm{~h}^{-1}$. It can be expected that for phenol, similar to nitrophenols, most of the phenol will be in the gas phase. Consequently the loss rate due to reaction in the condensed phase for the total atmospheric phenol concentration will be in the range of $10^{-3} \mathrm{~h}^{-1}$. The gas phase loss rate for phenol due to reaction with $\mathrm{OH}$-radicals for a global average $\mathrm{OH}$-radical concentration of $10^{6} \mathrm{~cm}^{-3}$ is approximately $0.1 \mathrm{~h}^{-1}$. This is a factor of 100 faster than the condensed phase removal rate.

Nitrophenols are substantially less reactive than phenol, for example the gas phase reaction rate constant of 4-nitrophenol with $\mathrm{OH}$ radicals is approximately a factor 80 slower than the reaction rate constant for phenol $+\mathrm{OH}$. When using this as scaling factor for the reactivity of 4-nitrophenol in the condensed phase the loss rate for 4-nitrophenol due to reaction in the condensed phase is in the range of $10^{-5} \mathrm{~h}^{-1}$, corresponding to an atmospheric residence time of more than 10 years. This is orders of magnitude slower than gas phase reactions of 4-nitrophenol and deposition rates for PM. There are large uncertainties in this comparison since the oxidant concentration in particulate matter in Toronto may be very different from that in fog at Davis. However, it is unlikely that this 
can compensate for the, compared to the gas phase, by a factor of 100 slower losses in the condensed phase.

Similarly, aqueous phase chemical reactions in rain are negligible compared the wet deposition. The residence time of rain drops in the atmosphere is several orders of magnitude lower than the life time of nitrophenols in the aqueous phase.

\section{Part 2. Numerical integration of the coupled differential equations}

For the sake of convenience, the reference carbon isotope ratio for the calculations are set to unity. In our model one isotopologue containing only ${ }^{12} \mathrm{C}$ atoms and one isotopologue containing one ${ }^{13} \mathrm{C}$ atom are considered. This is justified since the probability that in molecules containing only 6 to

8 carbon atoms more than one ${ }^{12} \mathrm{C}$ atoms is replaced by ${ }^{13} \mathrm{C}$ is negligible. For comparison with atmospheric measurements the concentration of the heavy isotopologue is corrected for the carbon isotope ratios of the precursor emissions by a factor of $\left(1-\delta^{13} C_{0}(\%) / 1000\right)$. In principle the concentration of the heavy isotopologue has to also to be corrected for the probability of being labeled with one ${ }^{13} \mathrm{C}$ atom by multiplication with a factor given by (number of carbon atoms $\mathrm{x}$ carbon isotope ratio (VPDB)). Calculation of the carbon isotope ratio from molecular ratios requires that the molecular ratio has to be divided by the value given by (number of carbon atoms $\mathrm{x}$ carbon isotope ratio (VPDB)). Since precursor, first generation and second generation product have the same number of carbon atoms omitting these corrections gives results identical to a calculation including both corrections. At the start of the numerical integration the concentrations of the isotopologues of first generation products (phenols) and second generation products (nitrophenols) are set to zero. The carbon isotope ratio of the second generation product is calculated from the concentrations of the light $\left({ }^{12} \mathrm{C}_{\text {prod }}\right)$ and the heavy $\left({ }^{13} \mathrm{C}_{\text {prod }}\right)$ isotopologues. 
$\delta^{13} C_{\text {prod }}=\left({ }^{13} C_{\text {prod }}-1\right) \times 1000$

Eq. S1

\section{Part 3. Quasi-steady state between precursor and intermediates}

For a set of coupled differential equations describing the formation of a product by a reaction sequence via unstable, highly reactive intermediates the concentration of the product can be approximated by a simple relation if the reaction rate for the reactive intermediate is much faster than the rate of reaction of the precursor.

$$
\begin{aligned}
& d C_{\text {pre }}=-C_{\text {pre }} k_{\text {pre }}[\mathrm{OH}] d t \quad \text { Eq. S2 } \\
& d C_{\text {int }}=-C_{\text {int }} k_{\text {int }} d t+{ }_{i n t} Y C_{\text {pre }} k_{\text {pre }}[\mathrm{OH}] d t \quad \text { Eq. S3 } \\
& d C_{\text {prod }}=-C_{\text {prod }} k_{\text {prod }} d t+{ }_{\text {prod }} Y C_{\text {int }} k_{\text {int }} d t \quad \text { Eq. S4 }
\end{aligned}
$$

Here $\mathrm{k}_{\text {pre }}$ is the rate constant for reaction of the precursor with the $\mathrm{OH}$-radical and $\mathrm{k}_{\text {int }}$ the pseudo first-order rate constant for reaction of the unstable intermediate, for example a methylhydroxycyclohexadienyl radical formed by the addition of an $\mathrm{OH}$-radical to toluene. The yield for the intermediate is int $\mathrm{Y} . \mathrm{C}_{\mathrm{pre}}, \mathrm{C}_{\mathrm{int}}$, and $\mathrm{C}_{\mathrm{prod}}$ are the concentrations of the precursor, intermediate and product of the reaction sequence, respectively. The rate constant describing the loss of product is $\mathrm{k}_{\text {prod }}$ and the yield of product from reaction of the intermediate is prod $\mathrm{Y}$.

If $\mathrm{k}_{\text {pre }} \mathrm{x}[\mathrm{OH}]$ is small compared to $\mathrm{k}_{\mathrm{int}}$ the rate of change of $\mathrm{C}_{\text {pre }}$ is small compared to the rate at which a steady state between formation and loss of the intermediate is achieved. This allows describing the concentration of the reactive intermediate by the following approximation. 
$C_{\text {int }}=\frac{\text { int }^{Y} C_{\text {pre }} k_{\text {pre }}[\mathrm{OH}]}{k_{\text {int }}}$

Eq. S5

The rate at which the product is formed then is independent of the reaction rate of the reactive intermediate.

$d C_{\text {prod }}=-C_{\text {prod }} k_{\text {prod }} d t+{ }_{\text {prod }} Y \quad{ }_{\text {int }} Y \quad C_{\text {pre }} k_{\text {pre }}[O H] d t \quad$ Eq. S6

Consequently, in this case the isotope ratio of the product depends on the overall mass dependence of the yield of the product and intermediate as well as the KIE for the initial reaction and the loss reaction of the product, but not on reaction rate or KIE for reactions of a highly reactive intermediates. Another consequence is that the overall isotope isotope fractionation resulting from mass-dependent yields for intermediates and products can be described by a single parameter. This simplifies the reaction scheme for calculation of carbon isotope ratios of nitrophenols, which proceeds via reactions of unstable intermediates.

In contrast to unstable, highly reactive intermediates reactivity of the phenolic intermediates is not sufficient to use a quasi steady state approximation (Figure S1). For very low PCA the carbon isotope ratio of the second generation product, in this study the nitrophenol, is determined by the isotope ratio of the precursor, the KIE for the reaction of the precursor and the first generation product with the $\mathrm{OH}$-radical as well as the mass dependence of the yields of first and second generation products. However, with increasing PCA the carbon isotope ratio of the second generation product becomes more and more dependent on reaction rate constants as well as the KIE for the removal of the second-generation products. An example is shown in Figure S2.

Part 4. Constraints for isotope fractionation based on experimental data 
The carbon isotope ratio at very low PCA is determined by the isotope ratio of the precursor and the sum of isotope fractionation effects for the reaction of the precursor and the first generation product with the $\mathrm{OH}$ radical as well as possible mass-dependence of the yields of the first and second generation products. We will refer to this sum as $\delta^{13} C_{\mathrm{PCA}=0}$. The upper limit for this value can easily be derived from ambient observations. Within the statistical uncertainty of the measurements the lower end of ambient observations of nitrophenol must be higher than or equal to $\delta^{13} \mathrm{C}_{\mathrm{PCA}=0}$. For 4-nitrophenol and the methylnitrophenols we use the average carbon isotope ratios of the lowest $10 \%$ of the ambient observations for comparison. For both groups the number of observations in this range exceeds 5. For 2,6 dimethyl-4-nitrophenol we use the lowest 5 values since the total number of available data points is only 18 and the lowest $10 \%$ of measured carbon isotope ratios consist of only 2 data points. To account for possible bias due to measurement errors we use the $99 \%$ confidence limit calculated from the number of data and the measurement error. The lower end of observed nitrophenol carbon isotope ratios most likely will be somewhat higher than $\delta^{13} \mathrm{CPCA}_{\mathrm{P}=0}$ since the actual PCA for these data points may not be zero. However, a substantial fraction of PCA derived from the carbon isotope ratios of light aromatic VOC is very small (Kornilova et al., 2016). For example the 25 percentiles of the derived PCA for benzene, toluene and xylene are $11 \times 10^{10}$ molecules s cm${ }^{-3}, 1.6 \times 10^{10}$ molecules s cm${ }^{-3}$, and $0.5 \times 10^{10}$ molecules s cm${ }^{-3}$, respectively. This corresponds to an increase relative to $\delta^{13} \mathrm{CPCA}_{\mathrm{P}=0}$ of $1.1 \%, 0.65 \%$, and $0.39 \%$, respectively. Using this possible increase as limit for corrections of the lower limits and a $99 \%$ confidence interval for carbon isotope ratio measurements lower limits for $\delta^{13} \mathrm{C}_{\mathrm{PCA}=0}$ are calculated. The resulting upper limits and lower limits are listed in Table S2. For comparison lower limits derived for PCA corresponding to the 10 percentile as well as 
the 50 percentiles of PCA are include in Table S2. Also included are the carbon isotope ratios calculated for PCA=0 based on Scenario 3.

For methylnitrophenols $\delta^{13} \mathrm{C}_{\mathrm{PCA}=0}$ can also be constraint using the laboratory studies published by Irei et al (2015). Figure S3 shows a plot of the average difference between the measured carbon isotope ratios of methylnitrophenols and calculated carbon isotope ratios as function of $\delta^{13} \mathrm{C}_{\mathrm{PCA}=0}$. The data points shown are the results of 500 calculations using randomly varying model parameters. The range of parameters used is given in Table S1. The best agreement between calculated and observed isotope ratios is found for $\delta^{13} \mathrm{C}_{\mathrm{PCA}=0}=-33.7 \%$. Based on the uncertainty of the laboratory measurements and the uncertainty of the calculation of methylnitrophenol carbon isotope ratios for a given value of $\delta^{13} \mathrm{C}_{\mathrm{PCA}=0}$ the standard error of this value is $0.7 \%$. The laboratory experiments reported in Irei et al. (2015) used toluene with a carbon isotope ratio of $-26.72 \%$ with an uncertainty of less than $0.1 \%$. The ambient carbon isotope ratio of toluene (Table 2) is $-27.6 \%$ with an uncertainty of $0.5 \%$. The resulting correction for $\delta^{13} \mathrm{C}_{\mathrm{PCA}=0}$ is $-0.9 \pm 0.5 \%$ and the best estimate of $\delta^{13} \mathrm{C}_{\mathrm{PCA}=0}$ for calculations of ambient methylnitrophenol carbon isotope ratios is $-34.6 \pm 0.9 \%$. Within its uncertainties this value is consistent with the upper limit derived from ambient observations. Within a $95 \%$ confidence there is also no statistically significant difference to the predictions from Scenario 3 and the lower limit calculated from the 10 percentile range of precursor PCA. However, $\delta^{13} \mathrm{C}_{\mathrm{PCA}=0}$ derived from the laboratory results is higher than the lower limits derived from 25 percentiles and 50 percentiles with a probability of $97 \%$ and $>99.9 \%$, respectively.

Uncertainty of the model predicted isotope ratios depend on the uncertainty of $\delta^{13} \mathrm{CPCA}_{\mathrm{PC}}$ as well as the uncertainty of the calculated change resulting from changes in PCA. By definition $\delta^{13} \mathrm{C}_{\mathrm{PCA}=0}$ is independent of the PCA, but the uncertainty of the change in carbon isotope ratio 
with increasing PCA also increases with PCA (Figure S2). We calculate the dependence of the uncertainty of PCA as function of PCA is by randomly varying the model parameters within there estimated uncertainty and determining the standard deviation of the isotope ratio for a given value of $\delta^{13} \mathrm{C}_{\mathrm{PCA}=0}$ as function of PCA. The dependence of the standard deviation of isotope ratios on PCA can be approximated by linear functions (Table S3). Uncertainty of $\delta^{13} \mathrm{C}_{\mathrm{PCA}=0}$ is calculated from upper and lower limits (Table S2) and the uncertainty of $\delta^{13} \mathrm{C}_{\mathrm{PCA}=0}$ calculated from the laboratory results of Irei et al. (2015). On average the uncertainty is $0.9 \%$ with a $99 \%$ confidence limit of $0.3 \%$. Details of the dependence of modeled isotope ratios on uncertainty of individual model parameters are shown in Figures S4 to S6.

\section{Part 5. Determination of a linear approximation for low PCA}

There is a substantial range of PCA where $\delta^{13} \mathrm{C}$ can be predicted by a linear approximation. Table S4 shows the regression parameters for Scenarios 2 and 3 for a linear approximation in a range where the difference between exact solution and linear approximation is within the typical measurement accuracy of $0.5 \%$ (Saccon et al., 2013). Except for 4-nitrophenol essentially all of the measurements reported by Saccon et al. (2015) are within the linear range of Scenario 3. For the range between $\mathrm{PCA}=0$ and the upper limit given in Table $\mathrm{S} 4$ the linear fit agrees with the results of the numerical integration within a range of $0.5 \%$.

\section{Part 6. Uncertainty of PCA derived from nitrophenol carbon isotope ratios}

Using the linear approximations in Table S4 uncertainty of isotope ratios can be converted into uncertainty of PCA derived from carbon isotope ratios of nitrophenols. The PCA independent uncertainty of $\delta^{13} \mathrm{C}_{\mathrm{PCA}=0}$ is estimated to be $0.9 \%$. For a linear dependence between PCA and carbon isotope ratio measurement uncertainty also contributes a PCA independent uncertainty. 
The combined PCA independent uncertainty is $1.0 \%$. Table S5 lists the parameters describing the PCA dependent uncertainty. Some details of the contribution of the uncertainty of individual model parameters to uncertainty of PCA are given in Table S6.

It is important that the difference in PCA derived from carbon isotope ratios of the same compound is only dependent on the measurement uncertainty and the difference in PCA, but not the uncertainty of $\delta^{13} \mathrm{C}_{\mathrm{PCA}=0}$.

\section{Part 7. Principles of the combined influence of mixing air masses with different PCA and deposition}

Atmospheric loss processes of nitrophenols significantly influence the weight of air masses with different PCA. Consequently, loss processes which do not result in isotope fractionation will impact the observed average PCA. Examples are shown in Figure S7. PCA depends on the physical age of the air mass as well as the $\mathrm{OH}$-radical concentration. Physical loss processes, for example deposition, usually do not depend on the OH-radical concentration. The combined loss rate of nitrophenols by deposition and reaction with $\mathrm{OH}$ radicals can therefore be described conceptually by the following expression:

$$
L_{N P}=-C_{N P}\left(k_{N P}^{O H}[O H]+k_{N P}^{d e p}\right) d t=-C_{N P} k_{N P}^{O H}[O H]\left(1+F_{r e l}\right) d t
$$

Here $\mathrm{L}_{\mathrm{NP}}$ is the total loss rate, $k_{N P}^{O H}$ the rate constant for reaction of the nitrophenol with $\mathrm{OH}-$ radicals, $\mathrm{C}_{\mathrm{NP}}$ the concentration of the nitrophenol, and $k_{N P}^{d e p}$ a constant describing the removal of nitrophenols by deposition. $\mathrm{F}_{\text {rel }}$ is defined as ratio of $k_{N P}^{d e p}$ and $k_{N P}^{O H}[O H]$. Consequently varying the ratio $F_{\text {rel }}$ between zero and any upper limit (UL) will cover the same range of possible combinations as independently changing $k_{N P}^{d e p}$ and $k_{N P}^{O H}[O H]$ as long as the ratio of $k_{N P}^{d e p}$ and $k_{N P}^{O H}[\mathrm{OH}]$ is between zero and the upper limit. 
Loss by deposition has in principle also a direct impact on the isotope fractionation as well as the overall loss rate of nitrophenols.

$$
\begin{array}{ll}
L_{N P-12}=-C_{N P-12}\left(k_{N P-12}^{O H}[O H]+k_{N P}^{d e p}\right) d t=-C_{N P-12} k_{N P-12}^{O H}[O H]\left(1+F_{r e l}^{12}\right) d t & \text { Eq. S8 } \\
L_{N P-13}=-C_{N P-12}\left(k_{N P-13}^{O H}[O H]+k_{N P}^{d e p}\right) d t=-C_{N P-12} k_{N P-13}^{O H}[O H]\left(1+F_{r e l}^{13}\right) d t & \text { Eq. S9 }
\end{array}
$$

The relative loss rate of isotopologues can then be described by:

$\frac{L_{N P-12}}{L_{N P-13}}=\frac{k_{N P-12}^{O H}\left(1+F_{r e l}^{12}\right)}{k_{N P-13}^{O H}\left(1+F_{r e l}^{13}\right)}=\frac{(\varepsilon+1)\left(k_{N P-12}^{O H}[O H]+k_{N P}^{d e p}\right)}{k_{N P-12}^{O H}[O H]+k_{N P}^{d e p}}$

Here $\varepsilon$ is the kinetic isotope effect for reaction of the nitrophenol with the OH-radical and the overall isotope fractionation can be described by an effective isotope effect ( $\left.\varepsilon_{\text {eff }}\right)$ which depends on the deposition rate.

$\varepsilon_{e f f}=\varepsilon \frac{\left(k_{N P-12}^{O H}[O H]+k_{N P}^{d e p}\right)}{k_{N P-12}^{O H}[O H]+k_{N P}^{d e p}}$

Consequently $\varepsilon_{\text {eff }}$ varies between $\varepsilon$ and zero, depending on the deposition rate. At low PCA the loss rate and KIE for reaction of the nitrophenols has only a negligible impact on the carbon isotope ratio of the nitrophenol (see Part 6). For higher PCA deposition can result in a systematic bias, depending on $\varepsilon$, the reaction rate constant and the deposition velocity. The largest influence of deposition is expected for 4-nitrophenol. At an average OH-radical concentration of $10^{6}$ molecules $\mathrm{cm}^{-3}$ the average PCA for 4-nitrophenol corresponds to 5.4 days. This is at the close to the estimated range for deposition of 8 days to 2 weeks (Chapter 3.5). In contrast the average PCA of methyl nitrophenol and dimethylnitrophenol correspond to only $12 \mathrm{~h}$ and $3 \mathrm{~h}$, respectively. 
To calculate the impact of deposition we use a life time of 10 days for loss of 4-nitrophenol by deposition and an average $\mathrm{OH}$-radical concentration of $10^{6}$ molecules $\mathrm{cm}^{-3}$. For the average 4nitrophenol carbon isotope ratio derived PCA of $4.7 \times 10^{11} \mathrm{~s}_{\text {molecules }} \mathrm{cm}^{-3}$ the change in carbon isotope ratio due to depositions is $0.14 \%$ and below a PCA of $9 \times 10^{11} \mathrm{~s}_{\text {molecules }} \mathrm{cm}^{-3}$ less than the measurement uncertainty of $0.5 \%$. 
Table S1. Parameters and their uncertainty ranges used for calculation of carbon isotope ratios of methylnitrophenols for Figure S2. There is no differentiation between different methylphenol or methylnitrophenol isomers since the uncertainty range used for the calculations includes the best estimates for all three studied methylnitrophenol isomers. The standard deviation given represents the standard deviation of the parameter for all calculations.

\begin{tabular}{|c|c|c|c|c|}
\hline Compound & Parameter & $\begin{array}{c}\text { Center } \\
\text { value }\end{array}$ & Range & $\begin{array}{l}\text { Standard } \\
\text { deviation }\end{array}$ \\
\hline \multirow{3}{*}{ Toluene } & $\mathrm{k}_{\mathrm{OH}}\left(10^{-12} \mathrm{~cm}^{3}\right.$ molec $\left.^{-1} \mathrm{~s}^{-1}\right)$ & 5.63 & 4.65 to 6.61 & 0.57 \\
\hline & $\varepsilon(\%)$ & 5.95 & 5.47 to 6.44 & 0.28 \\
\hline & $\delta^{13} C_{0}(\% \circ)$ & -26.72 & -26.69 to -26.75 & 0.02 \\
\hline \multirow{3}{*}{ Methylphenol } & $\mathrm{koH}\left(10^{-12} \mathrm{~cm}^{3}\right.$ molec $\left.^{-1} \mathrm{~s}^{-1}\right)$ & 40.9 & 26.7 to 55.2 & 8.5 \\
\hline & $\varepsilon(\%)$ & 1.0 & -0.7 to 2.7 & 1.0 \\
\hline & $\varepsilon_{\text {yield }}(\%)$ & 0 & -1.7 to 1.7 & 1 \\
\hline \multirow{3}{*}{ Methylnitrophenol } & $\operatorname{koH}\left(10^{-12} \mathrm{~cm}^{3}\right.$ molec $\left.{ }^{-1} \mathrm{~s}^{-1}\right)$ & 2.9 & 1.9 to 3.9 & 0.59 \\
\hline & $\varepsilon(\%)$ & 5.9 & 0.74 to 11.1 & 3.0 \\
\hline & $\varepsilon_{\text {yield }}(\%)$ & 0 & -1.7 to 1.7 & 1 \\
\hline
\end{tabular}

Table S2. Limits for the upper and lower end of $\delta^{13} \mathrm{C}_{\mathrm{PCA}=0}$ derived from measured ambient carbon isotope ratios of nitrophenols. The values for the lower limit use a correction based on the 10 percentile, 25 percentile and 50 percentile, respectively, of PCA reported by Kornilova et al. (2016).

\begin{tabular}{lccccc}
\hline Compound & $\begin{array}{c}\text { Lower limit } \\
\mathbf{5 0} \%)\end{array}$ & $\begin{array}{c}\text { Lower limit } \\
\mathbf{( 2 5} \%)\end{array}$ & $\begin{array}{c}\text { Lower limit } \\
\mathbf{( 1 0} \%)\end{array}$ & $\begin{array}{c}\text { Upper } \\
\text { limit }\end{array}$ & $\begin{array}{c}\text { Scenario 3 at } \\
\text { PCA=0 }\end{array}$ \\
\hline 4-Nitrophenol & $-38.4 \% 0$ & $-37.7 \% 0$ & $-37.3 \%$ & $-35.5 \% 0$ & $-36.9 \% 0$ \\
Methylnitrophenols & $-38.2 \% 0$ & $-36.7 \%$ & $-36.3 \%$ & $-35.3 \% 0$ & $-36.2 \% 0$ \\
2,6-Dime-4-NP & $-38.6 \%$ & $-36.6 \%$ & $-36.2 \%$ & $-35.2 \% 0$ & $-35.0 \% 0$ \\
\hline
\end{tabular}

Table S3. Parameters for linear fits describing the PCA dependent uncertainty of model calculated nitrophenol carbon isotope ratios.

\begin{tabular}{lccc}
\hline Compound & Intercept (\%) & $\begin{array}{c}\text { Slope } \\
\left(\mathbf{1 0}^{-\mathbf{1 2}} \mathbf{\%} \mathbf{c m}^{\mathbf{3}} \mathbf{M o l e c u l e}^{-\mathbf{1}} \mathbf{s}^{\mathbf{- 1}}\right)\end{array}$ & $\mathbf{R}^{\mathbf{2}}$ \\
\hline 4-Nitrophenol & $0.24 \pm 0.10$ & $4.6 \pm 0.4$ & 0.9233 \\
Methylnitrophenols & $0.05 \pm 0.02$ & $5.7 \pm 0.1$ & 0.9968 \\
2,6-Dime-4-NP & $0.1 \pm 0.07$ & $5.7 \pm 0.4$ & 0.9730 \\
\hline
\end{tabular}


Table S4. Linear approximation for dependence of carbon isotope ratios and PCA for nitrophenols formed by the photochemical oxidation of aromatic VOC.

\begin{tabular}{|c|c|c|c|c|c|}
\hline & $\mathbf{R}^{2}$ & $\begin{array}{c}\text { Slope }^{\mathrm{a}}\left(10^{-12} \% \text { }\right. \\
\left.\mathrm{cm}^{3} \mathrm{~s}^{-1} \text { molecules }^{-1}\right)\end{array}$ & $\begin{array}{c}\text { Intercept }^{\mathrm{a}} \\
(\%)\end{array}$ & $\begin{array}{c}\operatorname{Limit}_{(\% o} \delta^{13} C^{b} \\
\end{array}$ & $\begin{array}{c}\text { Initial } \\
\delta^{13} C^{c}(\%)\end{array}$ \\
\hline $4-\mathrm{NP}$ & 0.967 & $14.4(0.04)$ & $-37.9(0.005)$ & -34.8 & -38.4 \\
\hline 4-me-2-NP & 0.985 & $64.7(0.1)$ & $-35.7(0.005)$ & -30.1 & -36.2 \\
\hline 3-me-4-NP & 0.982 & $80.9(1.0)$ & $-35.7(0.006)$ & -30.7 & -36.2 \\
\hline 2-me-4-NP & 0.988 & $56.6(0.1)$ & $-35.7(0.004)$ & -29.6 & -36.2 \\
\hline 2,6-dime-4-NP & 0.985 & $89.4(0.1)$ & $-34.5(0.07)$ & -28.5 & -35.0 \\
\hline
\end{tabular}

${ }^{\mathrm{a}}$ from linear regression for a range with $<0.5 \%$ deviation from exact calculation; value in parenthesis is statistical error of linear regression. ${ }^{b}$ Upper end of the range where a linear fit with a PCA of zero as lower end does not deviate by more than $0.5 \%$ from the result of the numerical integration. ${ }^{c}$ Result of numerical integration for a PCA of zero. ${ }^{\mathrm{c}}$ From numerical integration.

Table S5. Parameters describing the uncertainty of PCA derived from nitrophenol carbon isotope ratios. The total uncertainty of the PCA can be calculated from: intercept +slope x PCA.

\begin{tabular}{lcc}
\hline & $\begin{array}{c}\text { Intercept } \\
\left(\mathbf{1 0}^{\mathbf{1 0}} \mathbf{\text { molecules } \mathbf { ~ c m }} \mathbf{~ c}^{\mathbf{3}}\right)\end{array}$ & Slope \\
\hline 4-NP & 7.0 & 0.32 \\
4-me-2-NP & 1.6 & 0.09 \\
3-me-4-NP & 1.3 & 0.07 \\
2-me-4-NP & 1.8 & 0.10 \\
2,6-dime-4-NP & 1.1 & 0.06 \\
\hline
\end{tabular}

Table S6. Change of average PCA derived from carbon isotope ratios of nitrophenols resulting from changes in carbon isotope ratios of emissions and isotope fractionation for reactions of intermediates. The calculations were based on in Scenario 3.

\begin{tabular}{lccccc}
\hline Change & 4-NP & 4-me-2-NP & 3-me-4-NP & 2-me-4-NP & 2,6-dime-4-NP \\
\hline $\begin{array}{l}\Delta \text { PCA }\left(10^{11} \mathrm{~s} \text { molecules } \mathrm{cm}^{-3}\right) \\
\text { for decrease in source signature }\end{array}$ & 1.6 & 0.14 & 0.14 & 0.18 & 0.09 \\
$\begin{array}{l}\left.\delta^{13} \mathrm{C}_{0}\right) \text { of } 1 \% 0 \\
\text { Resulting relative change (\%) }\end{array}$ & 34 & 35 & 28 & 36 & 45 \\
$\begin{array}{l}\Delta \text { PCA }\left(10^{11} \mathrm{~s} \text { molecules } \mathrm{cm}^{-3}\right) \\
\begin{array}{l}\text { for increase in fractionation for } \\
\text { reaction of intermediates by 1\%o }\end{array}\end{array}$ & 0.13 & 0.16 & 0.15 & 0.18 & 0.08 \\
\begin{tabular}{l} 
Resulting relative change (\%) \\
\hline
\end{tabular} & 3 & 25 & 36 & 32 & 52 \\
\hline
\end{tabular}


Figure S1. Example of the reaction time dependence of the carbon isotope ratio of a secondgeneration product for different values of the lifetime of the intermediate. The lifetime of the phenolic intermediate is calculated for an average $\mathrm{OH}$-radical concentration of $10^{6} \mathrm{~cm}^{-3}$.

Figure S2. Example of the dependence between the combined isotope effects during formation of the second-generation product (here methylnitrophenol) and calculated carbon isotope ratio for different PCA: $2 \times 10^{9} \mathrm{~s}$ molec cm $\mathrm{cm}^{-3}$ (diamonds), $10^{10} \mathrm{~s}$ molec $\mathrm{cm}^{-3}$ (squares), $5 \times 10^{10} \mathrm{~s} \mathrm{molec} \mathrm{cm}^{-3}$ (triangles), $2 \times 10^{11} \mathrm{~s}$ molec $\mathrm{cm}^{-3}$ (circles). The parameters are randomly varied over the ranges given in Table $\mathrm{S} 1$.

Figure S3. Average difference between carbon isotope ratios reported for methylnitrophenols formed by the $\mathrm{OH}$-radical initiated oxidation of toluene (Irei et al., 2015) and calculated carbon

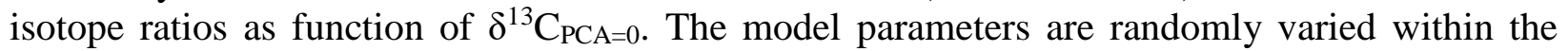
ranges given in Table $\mathrm{S} 1$.

Figure S4. Dependence between carbon isotope ratio and reaction time for PCA $\left(\int[\mathrm{OH}] \mathrm{dt}\right)$ predicted by the mechanistic model (Scenario 3) for different methylnitrophenol isomers.

Figure S5. Influence of changes in rate constant and kinetic isotope effect for the reaction of 2methyl-4-nitrophenol with the $\mathrm{OH}$-radical on the dependence between carbon isotope ratio and PCA $\left(\int[\mathrm{OH}] \mathrm{dt}\right)$. The calculations are based on Scenario 3 for the base case. The other curves show the results of calculations for kinetic isotope effects changed by approximately $\pm 1 \%$ ( $\varepsilon=5 \%$ and $\varepsilon=7 \%$ ) and the reaction rate constant changed by $\pm 30 \%$ (slow loss and fast loss). Also shown are the median, 10 and 90 percentiles as well as the lowest and highest carbon isotope ratios measured by Saccon at al. (2015) in an urban area.

Figure S6. Influence of uncertainty in rate constant and kinetic isotope effect for predictions of the carbon isotope ratio of 2-methyl-4-nitrophenol as function of PCA $\left(\int[\mathrm{OH}] \mathrm{dt}\right)$. The calculations are based on Scenario 3 and changes in reaction rate constants for the precursor are $\pm 10 \%$ (k pre $+10 \%$ and $\mathrm{k}$ pre $-10 \%$ ), for the reaction rate constant of the intermediate $\pm 20 \%(\mathrm{k}$ int $+20 \%$ and $\mathrm{k}$ int $-20 \%)$, and for the kinetic isotope effect of precursor reactions $\pm 0.5 \%$ o ( $\varepsilon$ pre $+0.5 \%$ and $\varepsilon$ pre $-0.5 \%$ ).

Figure S7. Impact of mixing two air masses characterized by different PCAs on PCA derived from carbon isotope ratios of benzene and 4-nitrophenol. Fig.a shows the PCA derived from the precursor (benzene, thin line) and the reaction product (4-nitrophenol, thick lines) for mixing air masses with $\int[\mathrm{OH}] \mathrm{dt}$ of $5 \times 10^{11} \mathrm{~s}$ molecules $\mathrm{cm}^{-3}$ (dashed line), $10^{12} \mathrm{~s}$ molecules $\mathrm{cm}^{-3}$ (solid line), and $3 \times 10^{12} \mathrm{~s}$ molecules $\mathrm{cm}^{-3}$ (dotted line), with air masses of lower values for $\int[\mathrm{OH}] \mathrm{dt}$ (x-axis). The relative weight of the aged air mass is $10 \%$ and the calculation does not consider loss of 4 nitrophenol by deposition. Fig. $b$ shows the impact of loss by deposition on the observed PCA for mixing of air masses with $\int[\mathrm{OH}] \mathrm{dt}=10^{12} \mathrm{~s}$ molecules $\mathrm{cm}^{-3}$ with an air mass of lower PCA (x-axis). The depositional loss rates are given as multiples of the chemical loss rate of 4-nitrophenol due to reaction with $\mathrm{OH}$-radicals. For comparison, the PCA calculated from the precursor carbon isotope ratio is also shown (solid line). 


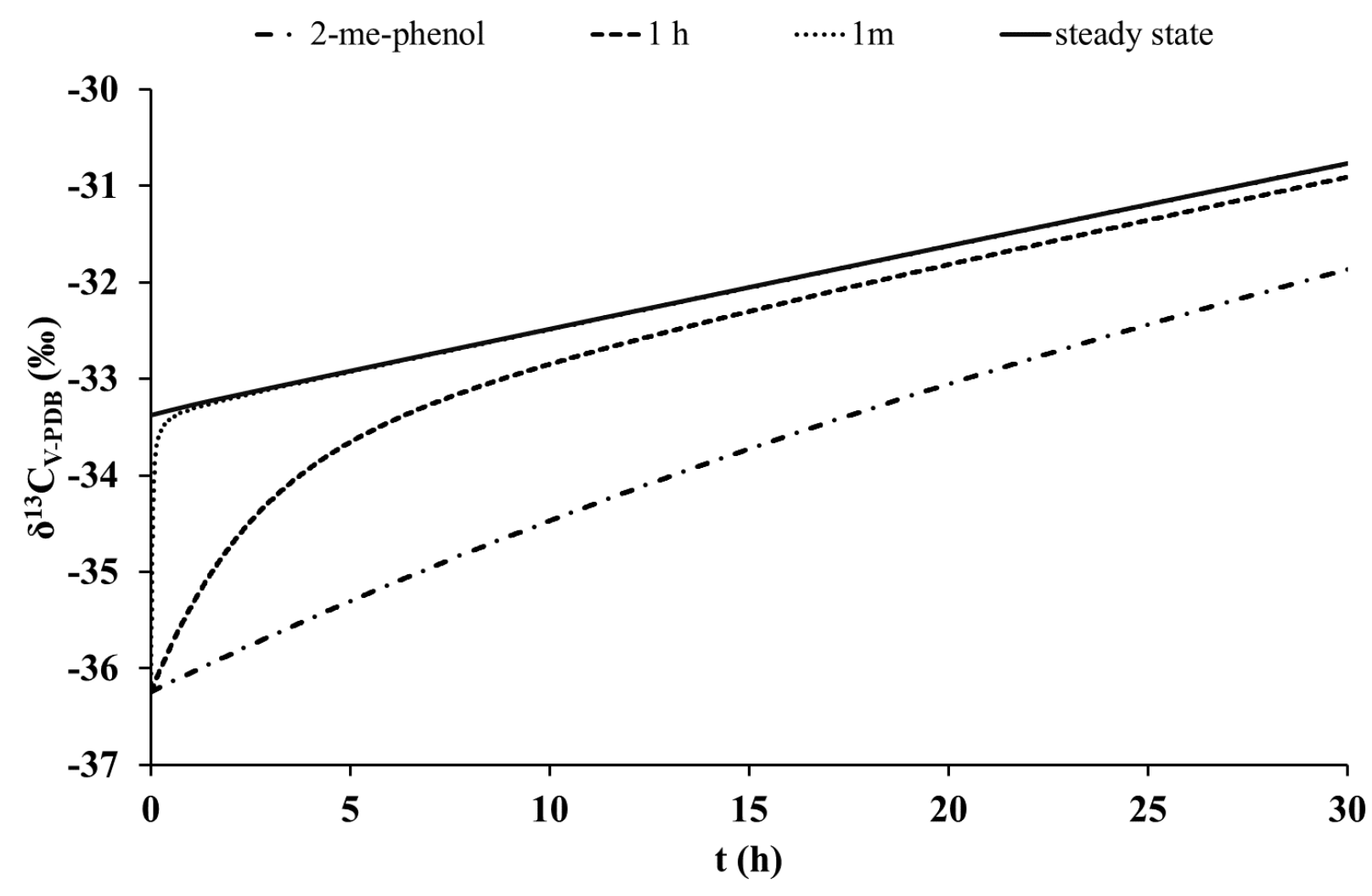

Figure S1. Example of the reaction time dependence of the carbon isotope ratio of a secondgeneration product for different values of the lifetime of the intermediate. The lifetime of the phenolic intermediate is calculated for an average $\mathrm{OH}$-radical concentration of $10^{6} \mathrm{~cm}^{-3}$. 


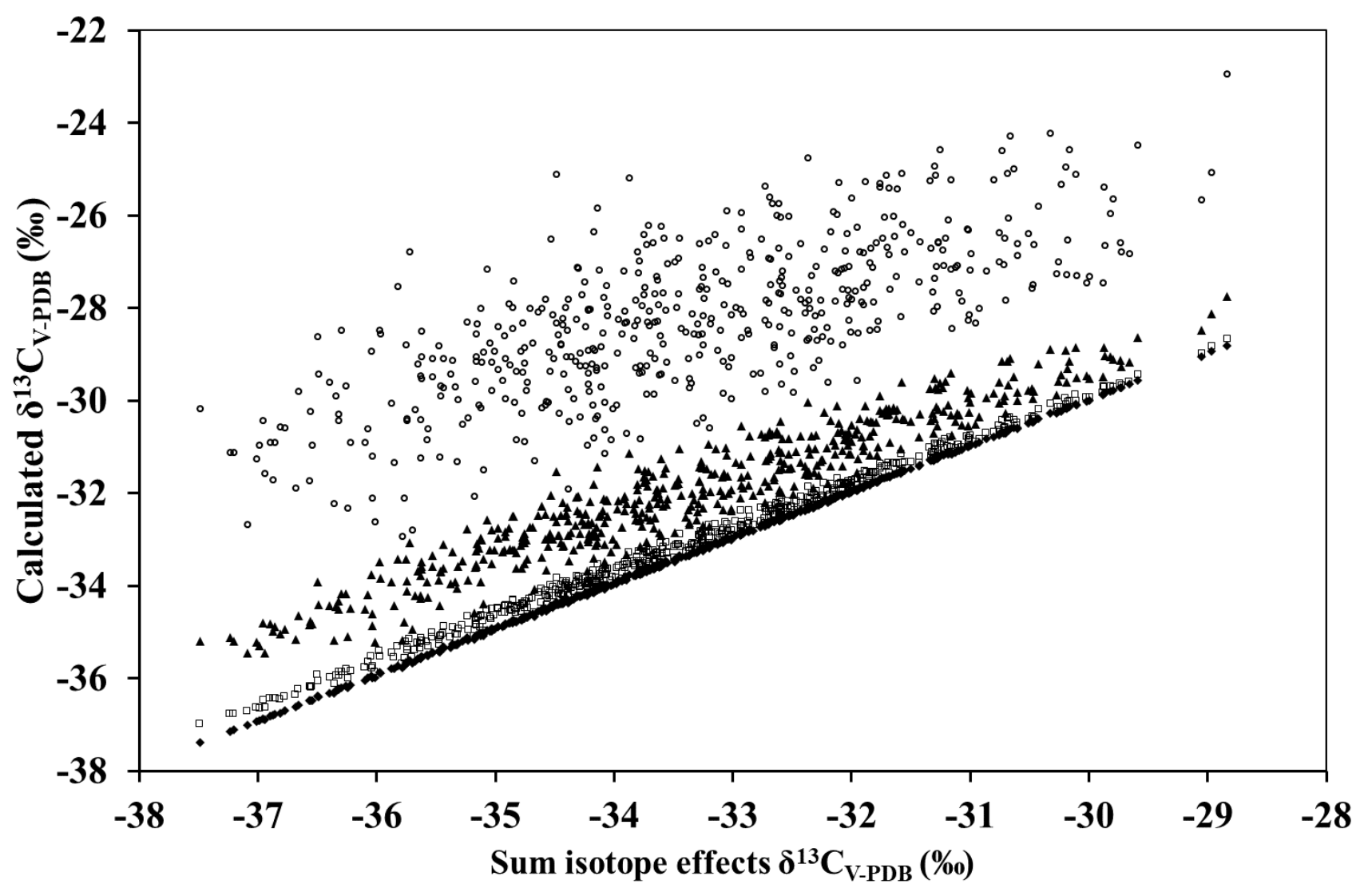

Figure S2. Example of the dependence between the combined isotope effects during formation of the second-generation product (here methylnitrophenol) and calculated carbon isotope ratio for different PCA: $2 \times 10^{9} \mathrm{~s}$ molec cm$~^{-3}$ (diamonds), $10^{10} \mathrm{~s}_{\text {molec cm}} \mathrm{c}^{-3}$ (squares), $5 \times 10^{10} \mathrm{~s}_{\text {molec cm}}{ }^{-3}$ (triangles), $2 \times 10^{11} \mathrm{~s} \mathrm{molec} \mathrm{cm}^{-3}$ (circles). The parameters and their uncertainties used in the calculation are listed in Table S1. 


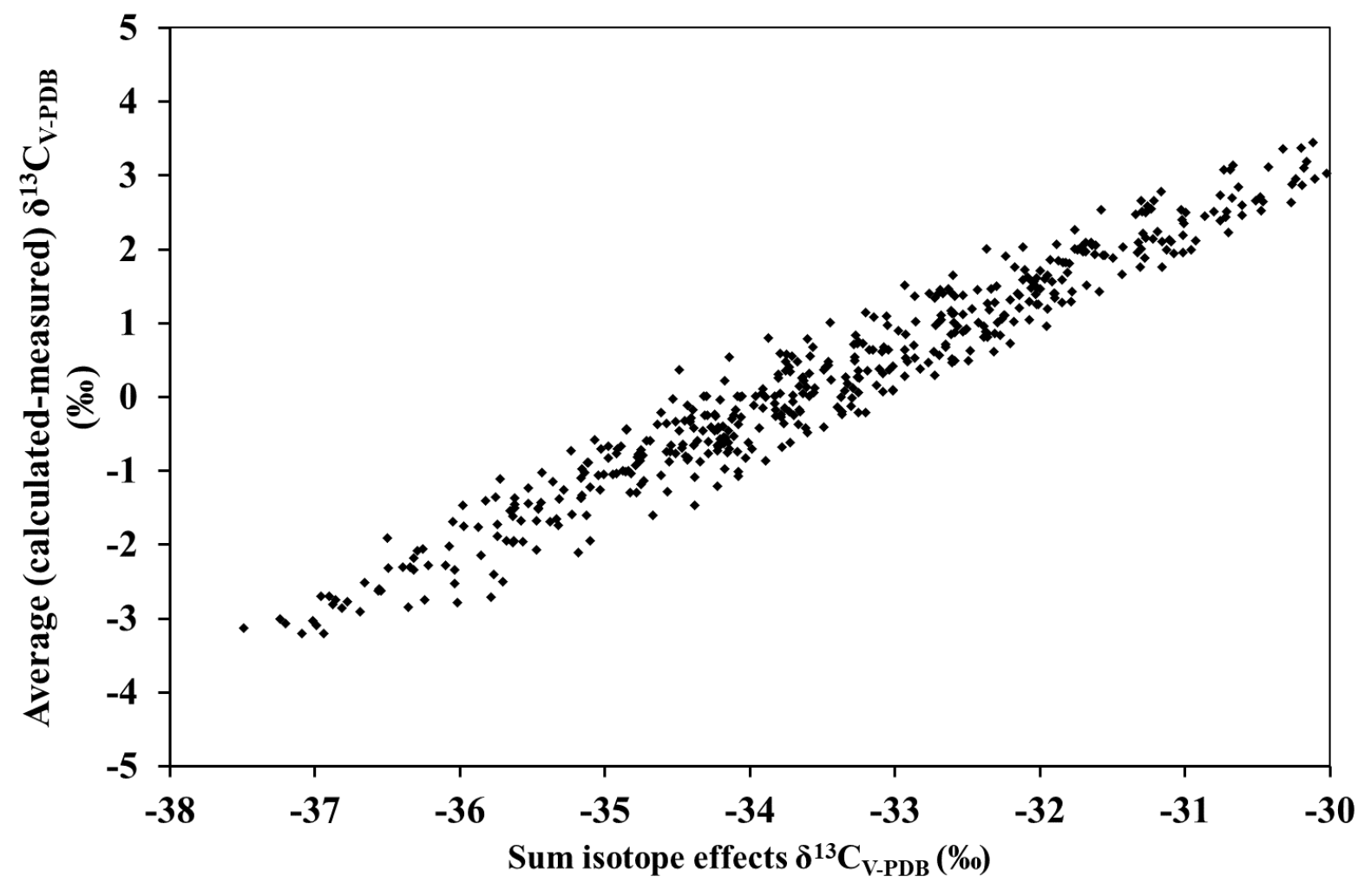

Figure S3. Average difference between carbon isotope ratios reported for methylnitrophenols formed by the $\mathrm{OH}$-radical initiated oxidation of toluene (Irei et al., 2015) and calculated carbon

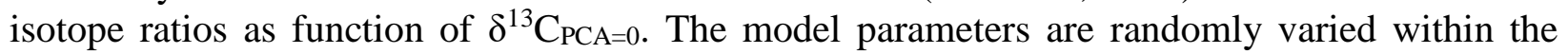
ranges given in Table $\mathrm{S} 1$. 


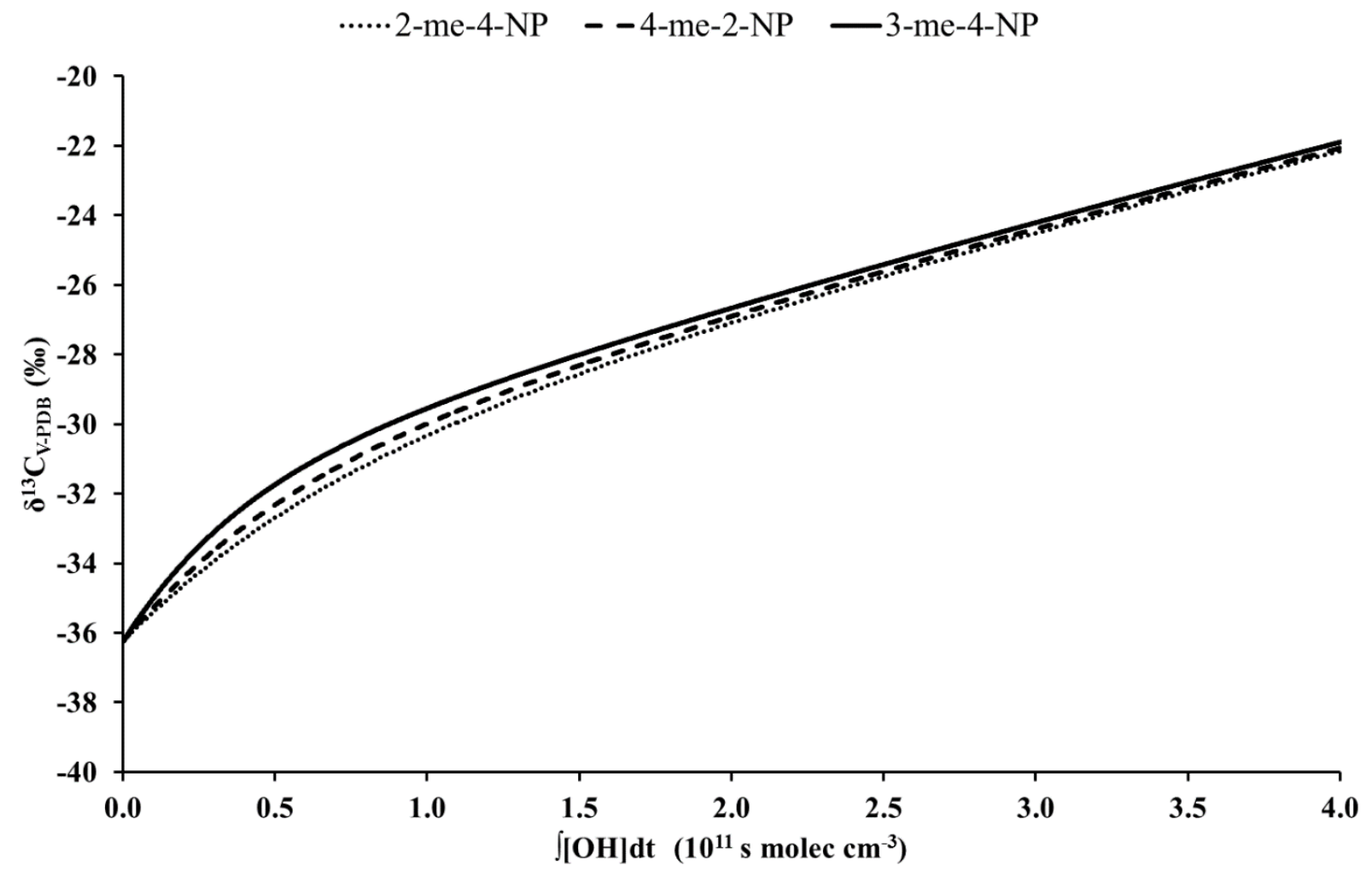

Figure S4. Comparison of the dependence between carbon isotope ratio and PCA $\left(\int[\mathrm{OH}] \mathrm{dt}\right)$ predicted by the mechanistic model (Scenario 3) for different methylnitrophenol isomers. 


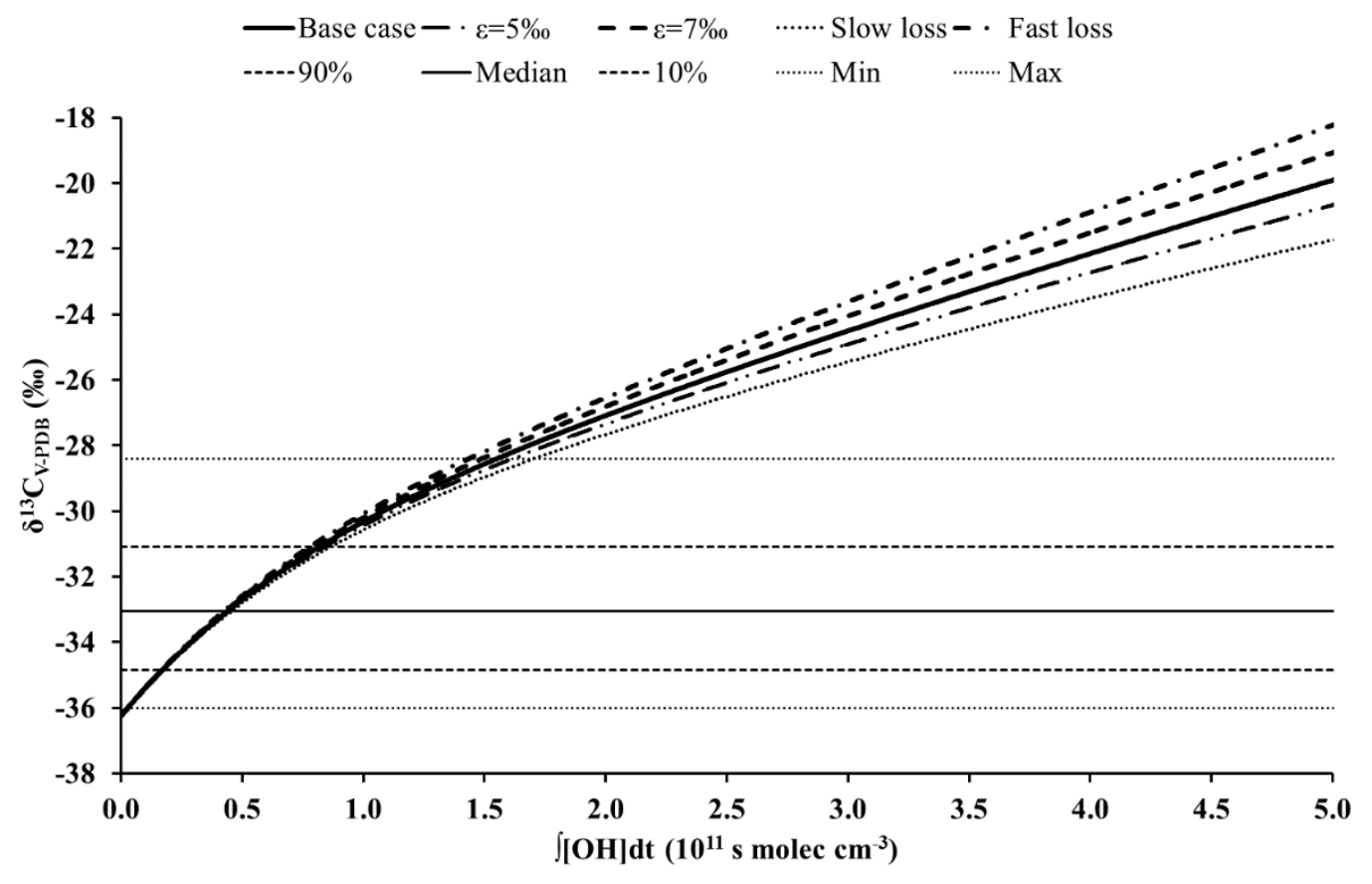

Figure S5. Influence of changes in rate constant and kinetic isotope effect for the reaction of 2methyl-4-nitrophenol with the OH-radical on the dependence between carbon isotope ratio and PCA $\left(\int[\mathrm{OH}] \mathrm{dt}\right)$. The calculations are based on Scenario 3 for the base case. The other curves show the results of calculations for kinetic isotope effects changed by approximately $\pm 1 \%$ ( $\varepsilon=5 \%$ and $\varepsilon=7 \%$ ) and the reaction rate constant changed by $\pm 30 \%$ (slow loss and fast loss). Also shown are the median, 10 and 90 percentiles as well as the lowest and highest carbon isotope ratios measured by Saccon at al. (2015) in an urban area. 


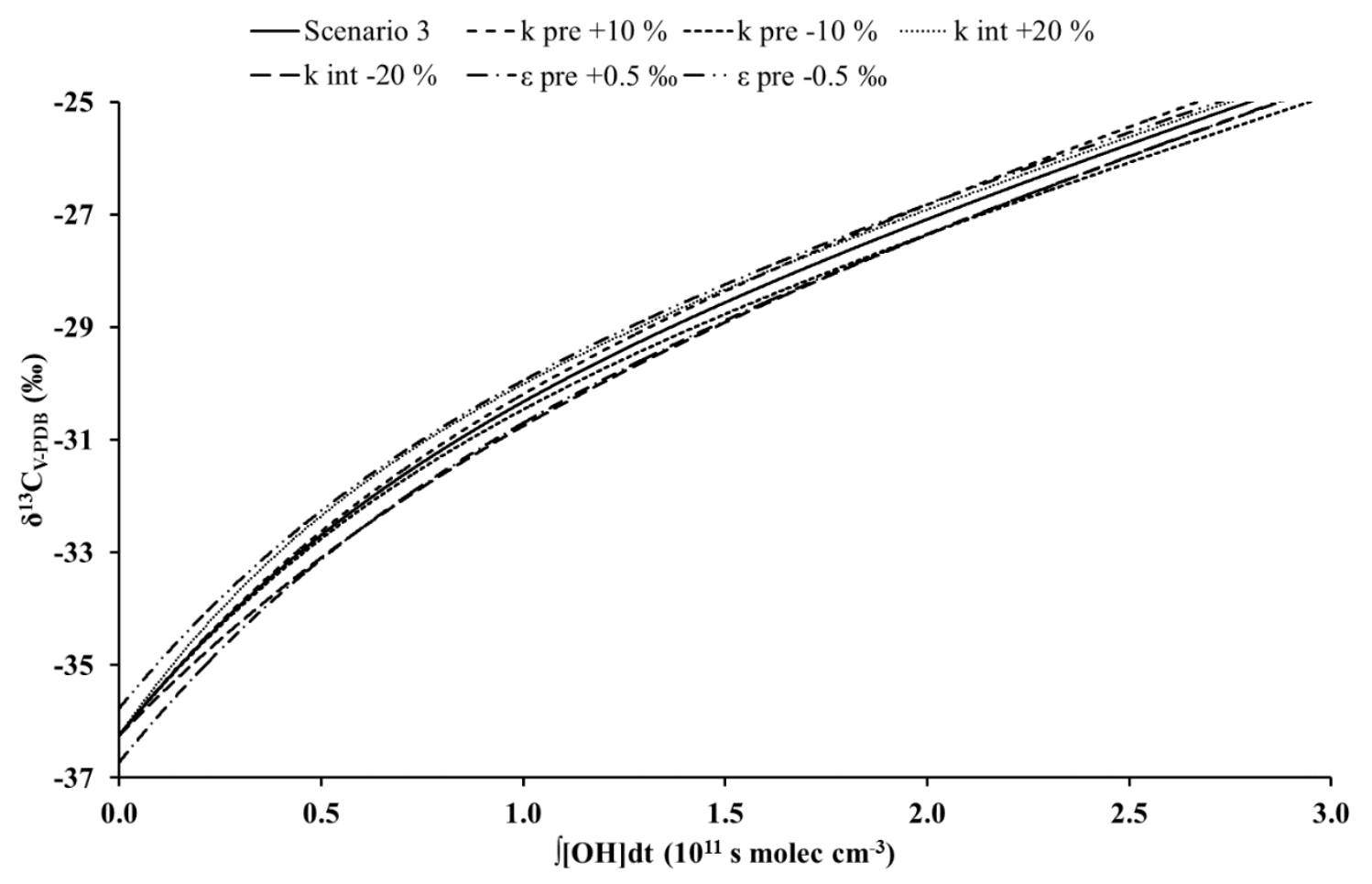

Figure S6. Influence of uncertainty in rate constant and kinetic isotope effect for predictions of the carbon isotope ratio of 2-methyl-4-nitrophenol as function of PCA $\left(\int[\mathrm{OH}] \mathrm{dt}\right)$. The calculations are based on Scenario 3 and changes in reaction rate constants for the precursor are $\pm 10 \%$ (k pre $+10 \%$ and $\mathrm{k}$ pre $-10 \%)$, for the reaction rate constant of the intermediate $\pm 20 \%(\mathrm{k}$ int $+20 \%$ and $\mathrm{k}$ int $-20 \%$ ), and for the kinetic isotope effect of precursor reactions $\pm 0.5 \%$ ( $\varepsilon$ pre $+0.5 \%$ and $\varepsilon$ pre $-0.5 \%$ ). 

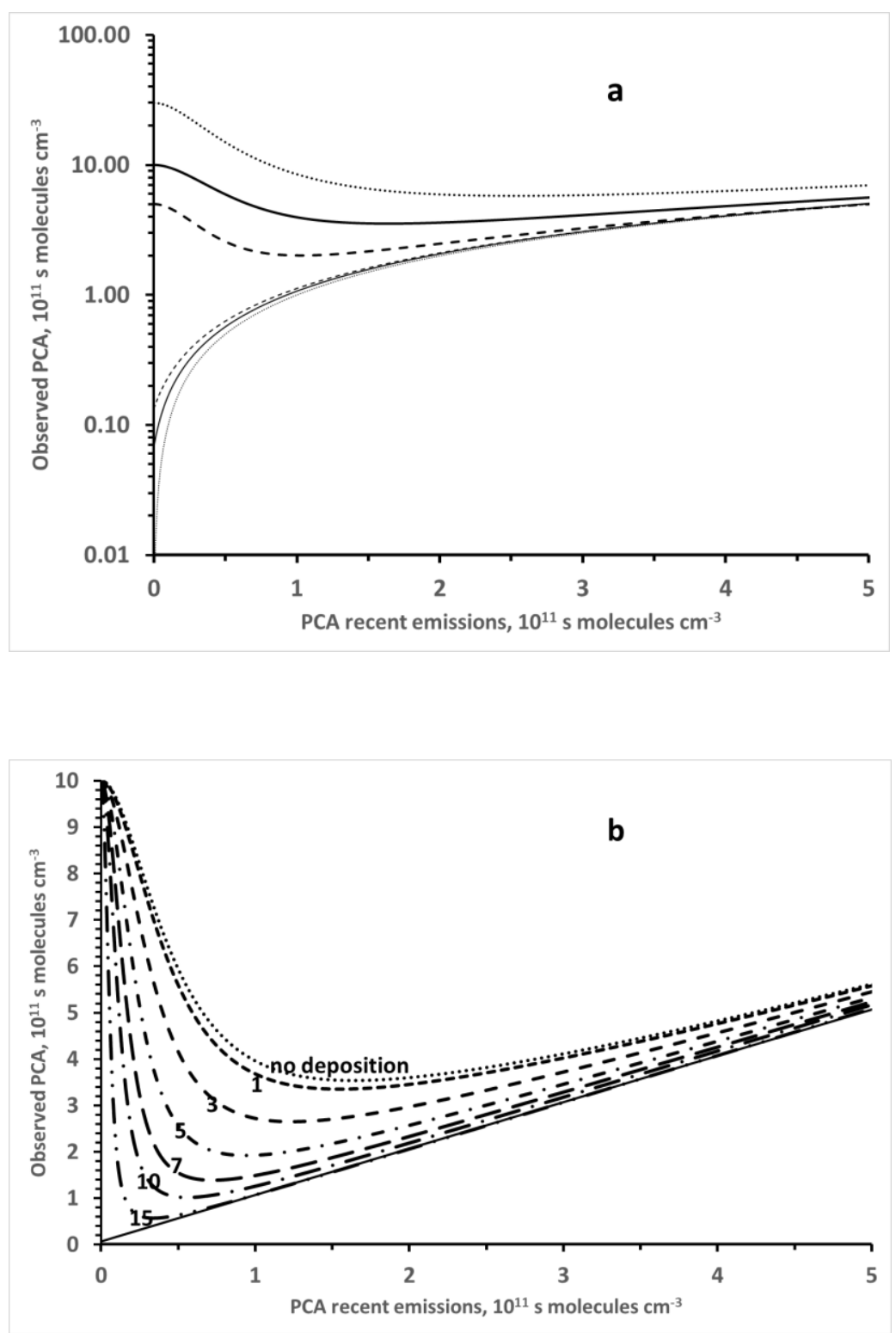

Figure S7. Impact of mixing two air masses characterized by different PCA on PCA derived from carbon isotope ratios of benzene and 4-nitrophenol. Fig. a shows the PCA derived from the precursor (benzene, thin line) and the reaction product (4-nitrophenol, thick lines) for mixing air masses with $\int[\mathrm{OH}] \mathrm{dt}$ of $5 \times 10^{11} \mathrm{~s}$ molecules $\mathrm{cm}^{-3}$ (dashed line), $10^{12} \mathrm{~s}$ molecules $\mathrm{cm}^{-3}$ (solid line), and $3 \times 10^{12} \mathrm{~s}$ molecules $\mathrm{cm}^{-3}$ (dotted line), with air masses of lower values for $\int[\mathrm{OH}] \mathrm{dt}$ (x-axis). The relative weight of the aged air mass is $10 \%$ and the calculation does not consider loss of 4nitrophenol by deposition. Fig. $b$ shows the impact of loss by deposition on the observed PCA for mixing of air masses with $\int[\mathrm{OH}] \mathrm{dt}=10^{12} \mathrm{~s}$ molecules $\mathrm{cm}^{-3}$ with an air mass of lower PCA (x-axis). The depositional loss rates are given as multiples of the chemical loss rate of 4-nitrophenol due to reaction with OH-radicals. For comparison, the PCA calculated from the precursor (benzene) carbon isotope ratio is also shown (solid line). 